\title{
Properties and Structure of Fiber-Reinforced Injection-Molded Part
}

\author{
Jiquan LI ${ }^{1, \mathrm{a}}$, Shaoguang YANG ${ }^{1, \mathrm{~b}}$, Fuyu XU ${ }^{1, \mathrm{c}}$ and Shaofei JIANG ${ }^{1, \mathrm{~d}}$ \\ ${ }^{1}$ College of Mechanical Engineering, Zhejiang University of Technology, Hangzhou, 310014, China \\ ahutli@163.com, ${ }^{\mathrm{b}} 1040154526 @ q q . c o m,{ }^{\mathrm{c}} 616156356 @ q q . c o m,{ }^{d}$ jsf75@zjut.edu.cn
}

\begin{abstract}
Fiber-reinforced plastics exhibit many merits and injection molding is one of the most common method for the production of plastics. Therefore, injection-molded fiber-reinforced plastic products have been widely used and their properties and structure were studied in the present work. The influences of fiber type, fiber content, and processing on the internal morphological structure of the injection-molded composite materials were investigated. Moreover, the change of performance of plastic products was analyzed.
\end{abstract}

\section{Introduction}

Fiber-reinforced plastic is the material consisting of an ordinary polymer as the matrix and reinforcing fiber such as carbon fiber (CF), glass fiber (GF), silicon nitride fiber (SiN), and natural fiber. The plastic has the following advantages: high specific strength, high specific modulus, good designability, great physical properties, and simple manufacturing process. Injection molding is the most common method for the production of plastic products. Hence, injection-molded fiber-reinforced plastics have been widely used, especially in automotive lightweighting, aviation, aerospace and other fields. Because of the characteristics of injection molding process, the distribution of fiber orientation, fiber crystallinity, and other morphological structures of the product will be heterogeneous in the material, and the change of these morphological structures will cause the variation of quality of products. In this paper, the macroscopic properties of current fiber-reinforced injection-molded parts such as tensile strength, modulus, impact toughness and appearance, as well as the internal morphological structures such as fiber orientation, interfacial interactions and crystallinity, were reviewed.

\section{Current work on properties of fiber-reinforced injection-molded parts}

Differences of processes, fiber types, fiber length, contents and other factors will result in variations of performance of the products. In terms of mechanical strength, Fu et al [1]

\footnotetext{
* Corresponding author:hutli@163.com
} 
studied the effect of content and length of short carbon fiber on the properties of composite materials, and it was indicated that the length of the fiber had a dominant influence on the tensile strength of composite rather than the volume fraction of the fiber. However, the tensile modulus was mostly dependent on the volume fraction. Gulrez et al [2] reported that the length of carbon fiber had a positive effect on the overall tensile strength, impact strength and elongation at break of composites. Hongmeng Ran et al [3] studied the reinforcement effects of carbon fibers and powder of carbon fibers on the mechanical properties of composites independently. With the increase of each reinforcing agent, the overall impact toughness and tensile strength increased in the first place and decreased afterwards, and the reinforcing function of carbon fibers was more significant. Wang et al [4] found that the mechanical properties of composite was dependent on the fiber content in the composite: with the increase of fiber content, the tensile strength and flexural strength increased while the impact strength firstly decreased and then maintained constant. Nayak et al [5] reported that when fiber content exceeded a critical value, the fiber in composite material products would agglomerate, resulting in voids inside the materials. Therefore, the transfer of effective stress was inhibited to reduce the impact strength of the stress. Zhang et al [6] tested the mechanical properties of CNTs-reinforced PP composites and found that both the tensile strength and modulus were greatly improved. It was elucidated that the presence of interfacial transverse crystals enabled the effective transfer of load from the PP matrix to fiber, enhancing the performance. Saujanya et al [7] suggested that the reinforcing effect of PET fibers, the higher crystallinity, and the presence of transverse crystals enhanced the bonding strength between matrix and fiber at the interface in PET/PP composites. In addition, the presence of PET fibers thinned spherulite, which thereby enhanced the impact strength of the composites.

With respect to appearance quality, the presence of fiber can reduce the warping deformation of products. Bo Yang et al. [8] studied the influence of processing parameters on the warping deformation of glass-fiber-reinforced polypropylene product. The results showed that fiber content and mold temperature dominated the warping deformation. The impact of melt temperature, injection time, and rate-pressure switch was minor. Aihua Xiong et al [9] also drew the same conclusion based on the Taguchi method for experiment design. Chen et al [10] studied the warping deformation of products with different fiber contents. As the content of fiber increased, the warping deformation increased and then decreased. Thus, warping deformation could be hindered by adding fiber. Daping Zuo [11] reported that the heterogeneous orientation of fibers caused warping deformation of glass-fiber-reinforced PA66. One can reduce warping deformation by optimizing processing parameters.

\section{Studies on morphological structures of fiber-reinforced injection-molded parts}

Studies on morphological structures of fiber-reinforced composites are focused on fiber orientation, interfacial bonding, and crystallinity.

With regard to fiber orientation, Fangfang He et al [12] investigated the structures of fiber-reinforced composites using different processing parameters. It was observed that the composite had a typical cortex-core structure: the orientation of fibers was homogeneous in the cortex while the orientation was heterogeneous in the core. Kim et al. [13] observed the orientation of glass fiber at weld lines using image processing technologies and found that the orientation was perpendicular to the direction of melt flow. Bin Qiu et al. [14] suggested that the coordination of melt viscosity and shear controlled fiber orientation. Ultra-high or ultra-low viscosity was not favorable to the orientation of fibers. Mortazavian et al. [15] tested the mechanical properties of fiber-reinforced composites. The results showed that the 
tensile strength and elastic modulus of the product in the flow direction were significantly higher than those of the product perpendicular to the flow direction. Moreover, the higher orientation degree of fibers was, the higher tensile strength and modulus were. Jie Yang et al [16] studied the orientation of fibers with different lengths inside products, and it was demonstrated that the orientation degree of fibers was favored by a smaller distance from the sprue, and the overall orientation degree of short fibers was higher than that of long fibers. This resulted from the weaker forces between short glass fibers during the injection molding process. Hence, the short fibers were susceptible to the shear within melt and exhibited a high orientation degree.

In addition, many researchers modified fibers to improve the interfacial bonding between the fiber and matrix and to enhance the reinforcing effect of fibers [17-19]. The modification methods include physical modification, chemical modification, acid etching, and base etching. Varga et al. [20,21] studied carbon-fiber-reinforced iPP composites. The carbon fiber had a strong inductive crystallization effect on iPP, and $\alpha$-transverse crystal layer was formed over the surface of the fiber. However, the transverse crystal layer could not be induced under static conditions in glass-fiber-reinforced iPP composites. Sun et al [22] investigated the effect of shear rate and shear time on the crystalline form at interface. The $\beta$ crystals at interface grew slowly at low shear rates while $\beta$ crystals could be instantly formed at high shear rates. Wang et al [23] subjected glass-fiber-reinforced PP composites to oscillatory shear during the curing step in manufacture process and interfacial transverse crystals were observed. The formation of the transverse crystals was ascribed to the strong shear in the shear field. Xu Zhao et al [24] reviewed the methods to obtain interfacial $\beta$ crystal layers, and discovered that interfacial $\beta$ transverse crystals could bond fibers with matrix to improve the impact strength and toughness of the parts.

Moreover, Ji et al [25] studied the changes of orientation and content of $\beta$ crystals within PET-fiber-reinforced isotactic polypropylene with WAXD. It was demonstrated that heterogeneous nucleation caused by the PET fibers could reduce the content of $\alpha$-crystal, and the content of $\beta$ crystals was significantly increased from the surface to the core. Stan et al [26] investigated the effect of content of MWCNTs fiber on polypropylene. As the content of MWCNTs increased, the overall crystallinity was slightly decreased. Panaitescu et al [27] treated hemp fibers with MAPP and Silan separately, and the treated fibers functioned as a reinforcing agent in polypropylene matrix. However, the internal crystallinity of products with/without the fibers was detected by XRD and DSC, which was almost unchanged. Zhenghong $\mathrm{Li}$ et al. [28] used an interfacial modifier to treat a bamboo-fiber-reinforced nylon composite. The glass-transition temperature of the treated composite was higher than that of pure nylon. Khattab et al [29] reported that VGCNF fiber elevated the overall beginning temperature of crystallization of LDPE, and the melt was cooled and solidified at a higher rate during the cooling process. The increase of crystallinity in the matrix of the fiber-reinforced composite would cause a tight arrangement of crystalline molecular chains and strong intermolecular interactions, and hence the performance of products can be improved to a certain extent [30].

\section{Conclusion}

The properties and structure of fiber-reinforced injection-molded parts were reviewed. In the current studies, the changes of morphological structures within injection-molded composites caused by fiber type, fiber content, and process were investigated. Moreover, the performance variation of the products was generally clarified. However, the mechanism of influence of morphological structures on the macroscopic properties of the products has not been systematically investigated. In addition, the surface quality of conventional injection-molded fiber-reinforced composites is poor and floating fibers were often 
observed, which is unfavorable to high-performance fiber-reinforced composites. Nevertheless, this phenomenon has not been fully investigated in the existing literatures.

\section{Acknowledgements}

This project was supported by Natural Science Foundation of Zhejiang Province (Grant No. LY15E050015).

\section{References}

1. Fu SY, Lauke B, Mäder E, Yue CY, Hu X. Tensile properties of short-glass-fiber-and short-carbon-fiber-reinforced polypropylene composites[J]. Composites Part A: Applied Science and Manufacturing, 2000, 31: 1117-1125.

2. Gulrez S K, Mohsin M A, Al-Zahrani S. Studies on crystallization kinetics, microstructure and mechanical properties of different short carbon fiber reinforced polypropylene (SCF/PP) composites[J]. Journal of Polymer Research, 2013, 20: 1-9.

3. Ran Hongmeng, Liao Qiuhui, Tao Zhengang, Lian Daojun, Zhang Yishun, $\mathrm{Wu}$ Huijun. Research on Mechanical Properties of Carbon Fiber Reinforced PP Composites[J]. Engineering Plastics Application, 2015, 41: 47-50 [in Chinese].

4. Wang W, Zhao G, Guan Y, Wang J, Wang C. Study on effects of short glass fiber reinforcement on the mechanical and thermal properties of PC/ABS composites[J]. Journal of applied polymer science, 2014; 131(17): 40697.

5. Nayak S K, Mohanty S. Sisal glass fiber reinforced PP hybrid composites: Effect of MAPP on the dynamic mechanical and thermal properties[J]. Journal of Reinforced Plastis and Composite, 2010, 29: 1551-1568.

6. Zhang S, Minus M L, Zhu L, Wong C-P, Kumar S. Polymer transcrystallinity induced by carbon nanotubes[J]. Polymer, 2008, 49: 1356-1364.

7. Saujanya C, Radhakrishnan S. Structure development and properties of PET fibre filled PP composites[J]. Polymer, 2001, 42: 4537-4548.

8. YANG Bo,SUN Ling. Influence of Processing Parameters on Short Glass Fiber Reinforced PP Injection Part Warpage [J]. CHINA PLASTICS, 2015, 1: 90-94.

9. Aihua Xiong,Hesheng Liu,Xingyuan Huang,Yibin Huang,Qingsong Jiang,Jiamei Lai.Influence of Processing Parameters on Injection Pressure and Warpage of Short-Glass Fiber Reinforced PP Injection-Molded Part [J]. POLYMER MATERIALS SCIENCE AND ENGINEERING, 2012, 28: 163-168.

10. Chen D, Lu G, He L, Li W, Yuan J. Warpage of injection-molded automotive B pillar trim fabricated with ramie fiber-reinforced polypropylene composites[J]. Journal of Reinforced Plastics and Composites, 2015: 1144-1152.

11. Zuo Daping, Zhang Y ihua, Rui Yulong. STUDY ON WARPAGE OF PA66/GF PART[J]. Engineering Plastics Application, 2006, 33: 23-25.

12. HE Fangfang, ZHOU Zhou, JIANG Bingyan. Prediction of melt flowability and fiber orientation for fiber reinforced polymer injection molding [J]. Acta Materiae Compositae Sinica, 2013, 1.128-133

13. Kim J, Kim H, Lee D. Study on fibre orientation of weld line parts during injection moulding of fibre reinforced plastic by image processing[J]. Materials Research Innovations, 2011, 15: 303-306.

14. Qiu Bin,Chen Feng.FIBREORIENTATION IN INJECTION MOULDING [J]. MODERN PLASTICS PROCESSING AND APPLICATIONS, 2005, 17: 50-52.

15. Mortazavian S, Fatemi A. Effects of Fiber Orientation and Anisotropy on Tensile Strength and Elastic Modulus of Short Fiber Reinforced Polymer Composites[J]. 
Composites Part B: Engineering, 2015. 72: 116-129.

16. YANG Jie,GAO Meng-luan, LI Zhi-tong,YIN Jing-jing,YAO Wen-hong,MA Ming-tu. Simulation of Injection Molding Process for Long /Short Fiber Reinforced Thermoplastic Composites [J]. CHINA PLASTICS INDUSTRY, 2015, 43: 81-84.

17. Sharma R, Maiti S. Effects of crystallinity of polypropylene (PP) on the mechanical properties of $\mathrm{PP} /$ styrene-ethylene-butylene-styrene-g-maleic anhydride (SEBS-g-MA)/teak wood flour (TWF) composites[J]. Polymer Bulletin, 2015, 72: 627-643.

18. Choi J K, Lee B W, Choi Y S, Jo B W, Choi S K. Reinforcing properties of poly (trimethyleneterephthalate) by a thermotropic liquid crystal polymer[J]. Journal of applied polymer science, 2015, 132(5):41408.

19. LI Jing, SHEN Shijie, LI Weina, YUAN Hui. Effects of acid modification on coupling agent amount of basalt fiber surface and mechanical property of BF/epoxy composites [J]. Acta Materiae Compositae Sinica, 31: 888-894.

20. Varga J, Karger-Kocsis J. Interfacial morphologies in carbon fibre-reinforced polypropylene microcomposites[J]. Polymer, 1995, 36: 4877-4881.

21. Wu C-M, Chen M, Karger-Kocsis J. Interfacial shear strength and failure modes in sPP/CF and iPP/CF microcomposites by fragmentation[J]. Polymer, 2001, 42: $129-135$

22. Sun X, Li H, Wang J, Yan S. Shear-induced interfacial structure of isotactic polypropylene (iPP) in iPP/fiber composites[J]. Macromolecules, 2006, 39: $8720-8726$.

23. Wang K, Guo M, Zhao D, Zhang Q, Du R, Fu Q, Dong X, Han C C. Facilitating transcrystallization of polypropylene/glass fiber composites by imposed shear during injection molding[J]. Polymer, 2006, 47: 8374-8379.

24. Zhao $\mathrm{Xu}$, Xie Mancun, Sun Weidong, Zheng Guoqiang. Research Progress on interface $\beta$-transcrystallization in Fiber Reinforced Isotactic Polypropylene Composites [J]. Plastics Science and Technology, 2011, 39: 90-93.

25. Ji C, Xie M, Chang B, Dai K, Wang B, Zheng G, Liu C, Shen C. $\beta$-Crystal in injection moulded poly (ethylene terephthalate) fibre/isotactic polypropylene composite[J]. Composites Part A: Applied Science and Manufacturing, 2013, 46: 26-33.

26. Stan F, Sandu L I, Fetecau C. Effect of processing parameters and strain rate on mechanical properties of carbon nanotube-filled polypropylene nanocomposites[J]. Composites Part B: Engineering, 2014, 59: 109-122.

27. Panaitescu D M, Vuluga Z, Ghiurea M, Iorga M, Nicolae C, Gabor R. Influence of compatibilizing system on morphology, thermal and mechanical properties of high flow polypropylene reinforced with short hemp fibers[J]. Composites Part B: Engineering, 2015, 69: 286-295.

28. LI Zheng-hong,CHEN Li-hui,HUANG Zu-tai. Dynamic Mechanical Thermal Analysis of Nylon Composite Reinforced with Bamboo Fiber [J]. Transactions of China Pulp and Paper, 2005, 20: 13-17.

29. Khattab A, Liu C, Chirdon W, et al. Mechanical and thermal characterization of carbon nanofiber reinforced low-density polyethylene composites[J]. Journal of Thermoplastic Composite Materials, 2013, 26(7):954-967.

30. Ning N, Fu S, Zhang W, Chen F, Wang K, Deng H, Zhang Q, Fu Q. Realizing the enhancement of interfacial interaction in semicrystalline polymer/filler composites via interfacial crystallization[J]. Progress in Polymer Science, 2012, 37: 1425-1455. 